Recepción: 20 / 01 / 2018

Aceptación: 14 / 02 / 2018

Publicación: 21 / 03 / 2018

Ciencias de la Educación

Artículo de Revisión

\title{
La dislexia como trastorno del aprendizaje en la educación básica
}

\author{
Dyslexia as a learning disorder in basic education
}

\section{Dislexia como transtorno de aprendizagem na educação básica}

\author{
Bayardo A. Rosales-Villareal ${ }^{\mathrm{I}}$ \\ bayardorosales@hotmail.com
}

Vicente I. Reyna-Moreira II

vicentereyna@hotmail.com

\author{
Wilman X. Ramírez-Rodríguez ${ }^{\mathrm{III}}$ \\ wl_manra@yahoo.com
}

\section{Correspondencia: bayardorosales@hotmail.com}

\footnotetext{
I Magister en Gerencia de Proyectos Educativos y Sociales, Doctor en Psicología educativa y orientación especialización psicología del adolescente, Licenciado en ciencias de la educación, Docente Universidad Laica Eloy Alfaro de Manabí, Manta, Ecuador.

II Magister en Gerencia Educativa, Licenciado en Ciencias de la Educación Espec. Psicología y Orientación Vocacional, Profesora de Segunda Enseñanza, Docente Universidad Laica Eloy Alfaro de Manabí, Manta, Ecuador.

III Magister en Educación Mención en Psicodidáctica, Magister en Desarrollo Humano y Comunitario, Psicólogo Clínico, Docente de la Universidad Técnica Luis Vargas Torres de Esmeraldas, Esmeraldas, Ecuador
} 


\title{
Resumen
}

La dislexia vinculada a los trastornos neurológicos provocados por traumatismos en el área del cerebro, vienen a constituir una de las causas del trastorno del aprendizaje durante el proceso de la educación básica en general. Este estudio presenta la evaluación de la dislexia como trastorno del aprendizaje en estudiantes de educación básica de las escuelas 6 de diciembre y San Isidro, adscritas a la provincia de Manabí. La metodología fue cualitativa con un enfoque de investigación -acción y de tipo descriptiva diagnostica. La población la constituyeron 82 estudiantes que se diagnosticaron con problemas de dislexia, quienes se organizaron en grupos de trabajo y recibieron se les aplicaron los reactivos psicológicos que ayudaron a confirmar el diagnóstico. Entre los resultados se pudo constatar que los alumnos evaluados en ambas instituciones presentan un coeficiente intelectual normal como lo demuestran los resultados de las pruebas aplicadas Cattel escala 1, la Evaluación de la Inteligencia General Factor G y la prueba de procesamiento fonológico y lectura inicial utilizado como material de apoyo para el diagnóstico de la dislexia.

Palabras claves: dislexia; trastorno del aprendizaje; reactivos psicológicos y educación básica.

\begin{abstract}
Dyslexia linked to neurological disorders caused by trauma to the area of the brain, come to constitute one of the causes of the disorder of learning during the basic education process in general. This study presents assessment of dyslexia as a learning disorder in students of basic education schools, December 6 and San Isidro, belonging to the province of Manabí. The methodology was qualitative with a focus on research - action and descriptive diagnosed. The population the 82 constituted them were students who were diagnosed with dyslexia problems, who were organized in working groups and received psychological reagents to they have helped to confirm the diagnosis. Among the results it was found that the students evaluated in both institutions have a normal IQ as evidenced by the results of the applied tests Cattel scale 1, evaluation of General Intelligence Factor $\mathrm{G}$ and test initial reading used as material support for the diagnosis of dyslexia and phonological processing.
\end{abstract}

Keywords: dyslexia; learning; reactive disorder psychological and basic education. 


\section{Resumo}

A dislexia associada a distúrbios neurológicos causados por lesões na área do cérebro, chega a constituir uma das causas do distúrbio de aprendizagem durante o processo de educação básica em geral. Este estudo apresenta a avaliação da dislexia como transtorno de aprendizagem em alunos do ensino fundamental das escolas de 6 de dezembro e de San Isidro, ligado à província de Manabí. A metodologia foi qualitativa com uma abordagem de pesquisa - ação e tipo descritivo diagnóstico. A população foi constituída por 82 estudantes diagnosticados com problemas de dislexia, que se organizaram em grupos de trabalho e receberam os reagentes psicológicos que ajudaram a confirmar o diagnóstico. Entre os resultados, verificou-se que as estudantes testadas em ambas as instituições têm QI normais como evidenciado pelos resultados dos testes aplicados escala Cattell 1 Avaliação da inteligência Geral Factor de L e testando o processamento inicial fonológica leitura e utilizado como material de suporte para o diagnóstico de dislexia.

Palavras chave: dislexia; distúrbio de aprendizagem; reagentes psicológicos e educação básica.

\section{Introducción}

La dislexia, en Benítez, Jiménez, y Osicka. (2000), es una alteración de origen neurológico, a menudo genética, que interfiere en la adquisición y el procesamiento del lenguaje. De gravedad variable, se manifiesta por las dificultades en el lenguaje receptivo y expresivo, incluido en el procesamiento fonológico, en la lectura, la escritura, la ortografía, la caligrafía y a veces en la aritmética. La dislexia no es el resultado de una falta de motivación, de una discapacidad sensorial, de un entorno educativo y ambiental desfavorable, o de otras condiciones limitativas, pero sí puede aparecer junto con ellas. Aunque la dislexia persistirá durante toda la vida, los individuos disléxicos a menudo responden bien a las intervenciones adecuadas. La dislexia, apunta Fernández. (1978), es consecuencia de una afectación cerebral adquirida después del nacimiento. Esta discapacidad se mantiene a lo largo del tiempo, en mayor o menor grado. Dato a destacar es que los niños que presentan dislexia tienen un nivel intelectual normal, y son capaces de desarrollar habilidades en mayor grado que los niños que no padecen esta enfermedad como por ejemplo: El proceso del pensamiento primario del disléxico es como el de una película sin sonido, que se crea a razón de 32 imágenes mudas por segundo. En un segundo, los pensadores verbales pueden tener de dos a cinco palabras individuales conceptualizadas, mientras que un 
pensador en imágenes tiene treinta y dos imágenes individuales conceptualizadas. Un pensador en imágenes podría pensar una sola imagen de un concepto, que requeriría cientos o miles de palabras para describirla. El pensamiento multidimensional usa todos los sentidos. Un aspecto de este tipo de pensamiento es la habilidad que tiene el pensador, de experimentar los pensamientos como realidades. En el disléxico, el impulso creativo es profundamente más intenso que en los individuos carentes de las habilidades básicas de aquél. La creatividad del disléxico se intensifica notablemente gracias al pensamiento con imágenes, al pensamiento intuitivo, al pensamiento multidimensional y a la curiosidad. La creatividad permite concebir cosas que en realidad no existen. A partir de esa experiencia, traemos las cosas a la existencia. Con frecuencia, los niños disléxicos no han desarrollado sus aptitudes de razonamiento y lógica, lo que han desarrollado es una variación de esta aptitud, que no sigue el modelo lineal del pensamiento verbal. Su razonamiento analítico y lógico se realiza por comparación, utilizando imágenes en vez de palabras. A veces los disléxicos pueden "ver" las respuestas de los problemas matemáticos sin utilizar lápiz ni papel. Resuelven los problemas, sin preocuparse de seguir los pasos convencionales. (PublicacionesDidacticas.com | No 71 junio 2016381 de 481). Si bien el proceso creativo y el proceso de aprendizaje del humano no son exactamente lo mismo, están tan íntimamente relacionados que no pueden ser separados. Cuando el aprendizaje es presentado de un modo experimental, los disléxicos pueden dominar muchas cosas más rápidamente de lo que tarde en entenderlas una persona común. Todas estas habilidades, si no son inhibidas externamente, pueden dar como resultado una inteligencia más alta de lo normal y una extraordinaria capacidad creativa. Tener dislexia no convierte automáticamente a alguien en un genio, pero es bueno para su autoestima saber que su mente funciona de la misma manera que la de algunos genios. Ante lo expuesto, en este artículo se caracteriza la dislexia como un problema de aprendizaje en estudiantes de educación básica.

\section{Desarrollo}

(Mediavilla, 2007), tras analizar distintas definiciones del término, concluye que la dislexia es un trastorno del lenguaje que afecta básicamente al aprendizaje de la lectura, pero que se manifiesta también en la escritura; se da en sujetos con un desarrollo cognitivo o inteligencia general normal o alta, que no padecen alteraciones sensoriales perceptibles y que han percibido instrucción adecuada. Es frecuente que los niños que padecen este problema tengan un desarrollo lingüístico 
tardío en los niveles fono articuladores y de fluidez, así como un aprendizaje y progreso lento de la lectura y la escritura.

La OMS, en la CIE-10, incluye la dislexia como "Síntomas de enfermedades que afectan al comportamiento y al conocimiento (R-48.0)" y “Trastornos del desarrollo psicológico (F80-89)", mientras el DSM-IV (en términos de psicología y psiquiatría), incluye la dislexia en los "Trastornos del aprendizaje", explicados de la siguiente forma: "rendimiento académico sustancialmente por debajo de lo esperado en el área afectada, considerando la edad del niño o adolescente, su inteligencia, y una educación apropiada para su edad (eje 1, Trastornos clínicos)”.

\section{Causas de la Dislexia}

Existen diversas teorías explicativas del origen de la dislexia, estableciéndose la distinción entre una dislexia "adquirida" (traumatismo o lesión cerebral) y una dislexia "evolutiva o de desarrollo" (causada por déficits madurativos), siendo este último el tipo más común y de mayor interés para este estudio. Entre las que se pueden considerar, de acuerdo a Suarez, A. (1995); causas hereditarias, causas debidas a retrasos madurativos psicosomáticos, trastornos del esquema corporal y de lateralidad, desorientación espacio-temporal, deficiencias en la coordinación viso-motora y la percepción auditiva y visual.

\section{Teoría explicativa basada en la Psicología del Aprendizaje}

Desde el campo de la Psicología del Aprendizaje, se rechaza el término dislexia y se sustituye por "retraso específico de la lectura" (Mediavilla, 2007, pág. 128) Se aceptan factores hereditarios, aunque las causas se atribuyen a deficiencias cognitivas (organización y codificación de la información) y al proceso de aprendizaje de la lectura-escritura. Las conclusiones que se pueden extraer de los numerosos estudios realizados para analizar las dificultades lingüísticas de los niños disléxicos y su relación con las capacidades cognitivas son (Mediavilla, 2007, pág. 131). El problema verbal no es de carácter conceptual o de procesamiento, sino de abstracción y generalización en la transferencia de información o la integración viso espacial.

Los disléxicos tienen dificultades en la lectura "porque traducen la entrada visual de las letras a un código de base sonora o hablada, innecesario para leer” (Rivas, 2007, pág. 26). Los niños disléxicos poseen escaso dominio del nivel sintáctico, baja fluidez verbal y vocabulario reducido. 


\section{Clasificación de la Dislexia}

Existen diversas clasificaciones de la dislexia, según se siga un enfoque neurológico, genético, psicológico o educativo. Tomando como fuente a (Mediavilla, 2007, págs. 140-142) podemos clasificar los diferentes tipos de dislexia como sigue:

Dislexia auditiva y visual: Tiene su origen en perturbaciones audio-fonológicas y video espaciales:

En la visual, el sujeto tiene dificultades para captar el significado de los símbolos en el lenguaje escrito (lenguaje oral pobre, baja comprensión lectora, ritmo de trabajo lento, errores en la copia, confusión temporal e inversión perceptiva).

En la auditiva, el sujeto no discrimina adecuadamente los sonidos (problemas en la discriminación de fonemas, errores ortográficos y de pronunciación, dificultad para recordar series).

Dislexia Disfonética (Auditiva), se caracteriza por déficit en el análisis de las palabras y habilidades relacionadas en la captación de las palabras. Son habituales los errores de sustitución semántica.

Dislexia Diseidética (Visual), se caracteriza por la existencia de déficit en la memoria visual, en la discriminación visual, y en las dificultades visoespaciales, lo que origina una lectura lenta. Son habituales los errores de inversiones visoespaciales de letras y palabras, y sustitución de una palabra o fonema de sonido similar.

Dislexia Mixta (Visoauditiva). Suele habitual que aparezcan mezclados los errores de los dos anteriores.

\section{Características de un disléxico en el aula.}

El maestro/a, y sobre todo el tutor/a, son las personas más idóneas para alertar del riesgo de dislexia en algún alumno/a concreto y, así, poder derivarlo al equipo de orientación. Por tanto, es necesario que, además de los signos para detectar la dislexia en distintas edades, tenga claro que algunas características de los niños disléxicos, las cuales se suelen atribuir a falta de atención, inmadurez, desinterés o baja capacidad intelectual, están provocadas por un trastorno neurológico 
de carácter persistente y específico. Dentro de estas características se pueden distinguir las siguientes: Son muy desorganizados y despistados; pierden mucho tiempo antes de comenzar a realizar una determinada tarea; les cuesta plantear y estructurar una historia para contarla o para escribirla; necesitan excesivo tiempo para realizar tareas de escritura; cuando no comprenden algo tienden a distraerse y a desconectar; persisten los problemas de disgrafía a pesar de trabajar continua y sistemáticamente la caligrafía; se cansan y distraen con facilidad mientras realizan tareas relacionadas con la lectoescritura debido al sobreesfuerzo que les supone; tienen dificultad para alinear la escritura, respetar los márgenes y los espacios; si se les pide que escriban con una grafía correcta y lentamente, comienzan con buena letra pero se va desestructurando a lo largo del renglón; no aprenden por tareas repetitivas, por lo que copian una misma palabra veinte veces y vuelven a escribirla mal en una redacción o dictado; se niegan a leer en voz alta en clase porque se sienten avergonzados y en ocasiones aparecen conductas negativas y desafiantes; se bloquean en los exámenes con facilidad, principalmente si saben que tienen un tiempo determinado y tienen unos días "buenos" y otros "malos" sin causa aparente.

\section{Errores específicos más frecuentes en lectura.}

\section{Para Sánchez, F. (2001), los errores más específicos son:}

Taquilexia: Consiste en un ritmo lector más acelerado de lo normal, ocasionando que en el transcurso de la lectura agregue, omita o imagine letras, palabras o frases que no constan en el texto, disminuyendo notablemente la comprensión lectora.

Bradilexia: Se refiere a una lectura con ritmo lento o aletargado en relación a su curso normal, hecho que influye directamente en la escasa comprensión de lo que el estudiante lee.

Lectura imaginativa: se presenta en estudiantes que, al no saber leer, imaginan lo que dice un texto a través de los dibujos representados en el mismo. También pueden darse en estudiantes que saben leer, pero van imaginando el complemento de las palabras al leer apenas la primera parte de cada una de ellas.

Lectura arrastrada: Es aquella en la cual el lector pone énfasis al pronunciar el sonido de los fonemas, especialmente en las s- rr 11. 
Lectura silenciosa: Se produce cuando el estudiante lee en voz baja antes de pronunciad las palabras que está leyendo.

Lectura mixta: En este tipo de lectura el estudiante puede cometer errores combinando las lecturas anteriormente indicadas.

\section{Trastornos Específicos de Aprendizaje en alumnos con dislexias}

Los errores en lecto escritura y calculo son conocidos con el nombre de trastornos específicos de aprendizaje o dislexia, que según el Dr. Iván Espinoza "es la dificultad de manejar las técnicas instrumentales básicas en niñas/os que han sufrido lenificaciones, madurativas con un coeficiente intelectual normal o cercano a la norma en ausencias de trastornos senso perceptivos grave" (pag.33).

Por este motivo, antes de diagnosticar la dislexia se debe aplicar un test de coeficiente intelectual (CI) pues se considera que un estudiante tiene dislexia cuando su CI se ubica dentro de los parámetros normales, inferiores o marginales. Además, es necesario aplicar pruebas de funciones básicas para estudiantes de primer año de educación básica general y de competencias curriculares, de segundo a séptimo año, así como es importante destacar cualquier problema de origen orgánico a nivel visual y/o educativo con los especialistas correspondientes.

\section{De acuerdo a los resultados obtenidos se determina el nivel de dislexia en el que se encuentra el estudiante, los cuales pueden considerarse de acuerdo a Frank H. D, Norman G (1988) como:}

Dislexia de primer nivel: En esta los estudiantes presentan dificultad para desarrollar las funciones básicas (destrezas). Se manifiesta en primer año de educación básica.

Dislexia de segundo nivel: Este tipo de dislexia se da cuando al finalizar el segundo año de educación básica en los niños no se integrado el proceso de lecto escritura y calculo.

Dislexia de tercer nivel: Es todo error específico de aprendizaje que se produce en la lectura, como escritura, calculo, a partir del tercer año de educación básica, cotejado en el nivel intelectual normal, inferior o marginal. 
Dislexia evolutiva: Corresponde a aquellos educandos que han pasado por los tres tipos de dislexia anteriormente mencionadas.

Dislexia congénita: Se presenta cuando los padres del estudiante, también han acusado al tipo de dislexia.

Dislexia de comprensión lectora: es la dificultad para comprender lo que el estudiante está leyendo.

El enfoque metodológico fue cualitativo con una perspectiva de investigación-acción, propuesta por Kemmis y Mctaggart (1992), como aquella que requiere planificar, actuar, observar y reflexionar más cuidadosamente, más sistemáticamente y más rigurosamente de lo que se suele hacer en la vida cotidiana, y significa utilizar las relaciones entre estos momentos distintos del proceso, como fuente de mejora del conocimiento. Para la recolección de la información, se organizaron grupos de trabajo de acuerdo al tipo de trastorno que presentaban, en este caso particular con trastornos de dislexia, a los cuales se le aplicaron los reactivos psicológicos que ayudaron a confirmar el diagnóstico, lo que posibilitó elaborar un banco de datos por Institución educativa, de igual manera se preparó una ficha de observación donde se plasmaron los datos de manera individual de cada uno de los estudiantes que presentaban dificultades escolares, problemas de aprendizaje y trastornos de aprendizaje.

El tipo de investigación fue descriptivo y de diagnóstico con todos los estudiantes de las instituciones educativas seleccionadas, mediante una selección de los alumnos y alumnas que presenten algún tipo de dificultad en el aprendizaje, se solicitó información de los docentes de los diferentes grados de las escuelas seleccionadas en el sector urbano y rural, se trabajó con el total de la población de las escuela que manifestaban algún trastorno de aprendizaje y la muestra la constituyeron 82 estudiantes que presentaban la dificultad del trastorno de dislexia del total evaluado a través de la observación mediante fichas individuales, fichas de problemas de aprendizaje, reactivos psicológicos, pruebas de evaluación de dislexia, entre estas, ejercicios de números y letras, de parafraseo y de omisión de letras, en la que se utilizaron baremos de calificación e interpretación. 


\section{Análisis y discusión de los Resultados}

Posterior a la aplicación de las pruebas psicológicas y de evaluación que permitieron conocer el trastorno de la dislexia en los alumnos y alumnas de las instituciones Educativa Seis de Diciembre del Sitio Piquigua y la Unidad Educativa San Isidro, amparadas en el convenio de vinculación con la Comunidad Educativa que tiene la Universidad Laica Eloy Alfaro, Extensión Bahía de Caráquez, se pudo confirmar los siguientes resultados:

Tabla 1. Problemas del trastorno de dislexia en estudiantes de educación básica

\begin{tabular}{|c|c|c|c|c|c|c|c|c|}
\hline \multirow[t]{2}{*}{ PROBLEMA } & \multicolumn{2}{|c|}{$\begin{array}{c}6 \text { de Dic } \\
6 \text { to Grado }\end{array}$} & \multicolumn{2}{|c|}{$\begin{array}{c}6 \text { de Dic } \\
7 \mathrm{mo} \text { Grado }\end{array}$} & \multicolumn{2}{|c|}{$\begin{array}{r}\text { San Isidro } \\
7 \text { mo.Grado }\end{array}$} & \multicolumn{2}{|c|}{$\begin{array}{l}\text { San Isidro } \\
\text { 6to.Grado }\end{array}$} \\
\hline & Fr & $\%$ & Fr & $\%$ & $\mathbf{F r}$ & $\%$ & $\mathrm{Fr}$ & $\%$ \\
\hline Lectura & 8 & 44.44 & 8 & 42,10 & 7 & 21.21 & 3 & 9.67 \\
\hline Taquilexia & 3 & 16.66 & 2 & 10,52 & 2 & 6.06 & 1 & 3.22 \\
\hline Bradilexia & 2 & 11.11 & 3 & 15,78 & 2 & 6.06 & 1 & 3,22 \\
\hline Lectura silenciosa & 1 & 5,55 & 2 & 10,52 & 1 & 3,03 & & \\
\hline Lectura imaginative & & & & & 1 & 3,03 & & \\
\hline Lectura arrastrada & 1 & 5,55 & & & & & 1 & 3,22 \\
\hline $\begin{array}{l}\text { Dificultades al realizar } \\
\text { operaciones básicas }\end{array}$ & 3 & 16,66 & 6 & 31,57 & 10 & 30,30 & 4 & 12,90 \\
\hline No lee & & & & & & & & \\
\hline Dislexia Evolutiva & 2 & 11,11 & 2 & 10,52 & 2 & 6,06 & 4 & 12,90 \\
\hline
\end{tabular}




\section{Fuente: Elaboración Propia.}

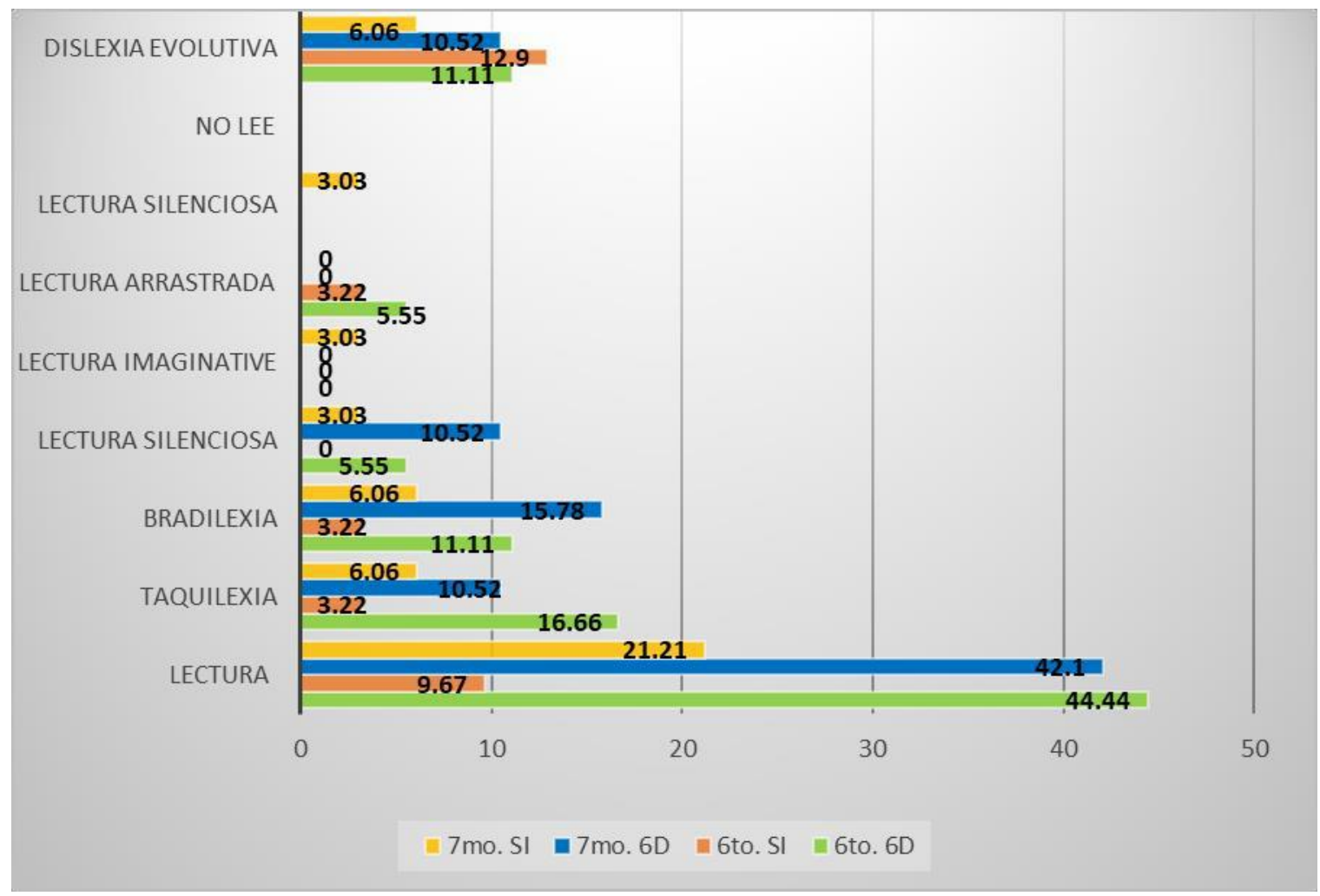

\section{Grafico 1. Problemas del trastorno de dislexia en estudiantes de educación básica}

Fuente: Elaboración Propia.

En la tabla y grafico 1, se presentan los resultados de la aplicación de las pruebas en alumnos del sexto y séptimo grado de las escuelas 6 de diciembre y San Isidro, en la que se pudo evidenciar que entre los alumnos del sexto grado de la unidad educativa seis de diciembre, se evaluaron 10 alumnos con problemas de lectura, 4 con taquilalia, 3 con bradilexia, 1 con lectura arrastrada y 1 con lectura silenciosa. Posterior a la aplicación de las pruebas Cattel escala 1, Evaluación de la Inteligencia General Factor G, de forma grupal, se constató que dos alumnos de los investigados se evaluaron con problemas de dislexia y con un coeficiente intelectual normal.

Posteriormente se procede a la aplicación de las pruebas correspondientes a los alumnos del séptimo grado de educación básica de la Unidad Educativa Seis de Diciembre, encontrando que 8 alumnos tienen problemas en lectura, 2 con taquilexia, 3 bradilexia, 2 con lectura silenciosa, 3 
lectura poco comprensible, 2 alumnos con posible dislexia evolutiva y 3 alumnos no presentan dificultades de aprendizaje.

En cuanto a la unidad Educativa San Isidro, del total de alumnos investigados en el séptimo año de educación Básica se determinó que 7 alumnos tienen problemas en lectura, 2 alumnos presentan taquilexia, 2 con bradilexia, 1 lectura silenciosa, 1 lectura imaginativa. Por otro lado, de un total de 31 alumnos investigados del sexto grado 3 presentan problemas en lectura, 1 presenta taquilexia, 1 bradilexia, 1 lectura arrastrada. Cabe recalcar que en la mayoría de casos los niños con dislexia también presentan problemas de disgrafia y discalculia en esta investigación.

En el caso particular del diagnóstico realizado a los alumnos en esta investigación, se constató que existe un 12, 9 del sexto grado de la unidad educativa San Isidro con dislexia evolutiva y el 44,44 con problemas de lectura del sexto grado de la Unidad Educativa 6 de diciembre. Se destaca el hecho en la cual, los alumnos del séptimo grado no presentaron los mayores porcentajes de indicadores de esta dificultad de aprendizaje.

\section{Conclusiones}

Los alumnos evaluados en ambas instituciones presentan un coeficiente intelectual normal como lo demuestran los resultados de las pruebas aplicadas Cattel escala 1, Evaluación de la Inteligencia General Factor $\mathrm{G}$ al aplicarlo de manera grupal, y la prueba de procesamiento fonológico y lectura inicial utilizado como material de apoyo para el diagnóstico de la dislexia. Dicha evaluación conto con la información obtenida por docentes y padres de familia de la Institución Educativa.

Del total de alumnos investigados en la unidad educativa Seis de Diciembre del sitio Piquigua perteneciente al Cantón Sucre de la Provincia de Manabí se determinó que la mayoría de los alumnos tienen problemas en la lectura, además se pudo observar que existe un problema generalizado de no saber escuchar, no seguir órdenes y problemas de psicomotricidad, no mueven las manos de acuerdo a su desarrollo y edad cronológica, tomando en cuenta que son alumnos de grados superiores de educación Básica, de igual manera existen alumnos que no toman apuntes. 
Del total de alumnos investigados en la Unidad Educativa de San Isidro perteneciente al Cantón Sucre de la Provincia de Manabí, se determinó que presentan problemas en la lectura, también se pudo observar problemas de psicomotricidad no mueven las manos de acuerdo a su desarrollo y edad cronológica tomando en cuenta que son alumnos de grados superiores de educación Básica, de igual manera existen alumnos que no cogen apuntes, se observa que tienen dificultades para escuchar y seguir órdenes.

\section{Referencias Bibliográficas}

Benítez, Jiménez, y Osicka. (2000). Neurobiología y neurogenética de la dislexia. Neurología, 25 , 9, 563-581.

Fernández F, LLopis A y Pablo de Riesgo C. (1978). La dislexia, Origen, diagnóstico, recuperación. Barcelona. Editorial CEPE. $4^{\mathrm{a}}$ edición.

Fernández. (1978). Trastornos del Aprendizaje o Dificultades en el Aprendizaje. - CELAEE. La Habana.

Frank H. D, Norman G (1988). Dislexia. Aspectos psicológicos y neurológicos. Editorial Labor. Kemmis, S. y McTaggart, R (1992). Cómo planificar la investigación acción. Argentina. Editorial Laerths.

Mediavilla, (2007). La cuestión de la dislexia y la disgrafía en la adquisición de segundas.

Recuperado en:

https://www.mecd.gob.es/dam/jcr:86c4fc9a-ba07.../2010-bv-11-13grande-pdf.pdf

Raymond D. Adans, Maurice Vido. (1981). Principios de neurología. Editorial Reverte.

Ribas, M y Fernández, P. (1997). Dislexia, disortografía, disgrafia. Ediciones Pirámide.

Sánchez, F. (2001). Las dificultades en el aprendizaje de la lectura. Madrid: Síntesis

Suarez, A. (1995). Dificultades en el aprendizaje. Un modelo de Diagnóstico e Intervención. Madrid: Editorial Aula XXI. Santillana.

Thomson, M.E (1992). Dislexia. Su naturaleza, evaluación y tratamiento. Colombia. Editorial Alianza Psicología. 